\title{
Characterizing the bacterial community in bioflocs, culture water and intestines of GIFT tilapia (Oreochromis niloticus) reared in a biofloc technology (BFT) system
}

\author{
Yang Zhang \\ Shanghai Ocean University \\ Baoxin Cao \\ Shanghai Ocean University \\ Godwin Abakari \\ Shanghai Ocean University \\ Hongxin Tan \\ Shanghai Ocean University \\ Guozhi Luo( $\square$ gzhluo@shou.edu.cn ) \\ Shanghai Ocean University
}

\section{Original article}

Keywords: Bacteria community, Bioflocs technology aquaculture system, Nitrification, Heterotrophic assimilation

Posted Date: October 9th, 2020

DOI: https://doi.org/10.21203/rs.3.rs-88252/v1

License: (c) (1) This work is licensed under a Creative Commons Attribution 4.0 International License. Read Full License 


\section{Abstract}

GIFT Oreochromis niloticus was cultured in a bio-floc technology (BFT) system to identify the floral structure of the biofloc water and in the intestine of the fish. High-throughput sequencing technology was used to detect the microbes in the culture water, in the intestines and gills of farmed fish. The effective sequence coverage rate of each sample exceeded $99 \%$ and the sequencing results were true and reliable. The results show that according to Chao1 and Simpson indices, the microbial richness and diversity of flocs increase with the increase of culture time. Flocs initially favoured the thickwalled bacterium ( Firmicutes ) as the dominant fungi with abundance of $86 \%$, whiles the rest were all less than $10 \%$ in abundance. At the end of the experiment the abundance of Chlorofiexi was $43 \%$, Proteobacteria $26 \%$, and Bacteroidetes $12 \%$. During the early stages, Bacillus was the most dominant group of about $86 \%$ abundance. However, this declined towards the end of the breeding period and the abundance was recorded to reduce to about $3 \%$. The highest abundance was associated with the bacterial described as unclassified species called $\mathrm{N}$ orank-f-caldilineaceae representing $40 \%$ and the abundance of Flavobacterium found to be $2 \%$. The dominant bacteria in the intestinal tract of fish were Proteobacteria (35\%), Bacillus (16\%) and Cetobacterium (13\%). The main heterotrophic assimilation functions in the BFT system were bacillus and chlorocampylobacter. However, flavobacterium was found in the BFT system indicating the presence of on-going denitrification

\section{Introduction}

In aquaculture practice, farmers attempt to achieve higher yields by adopting high-density culture of fish and through the utilization of high-protein feeds. In addition, aquaculturist also promote nitrogen utilization in aquatic animal feed which is often maintained in the range of $25-35 \%$ in an effort to increase production (Zohreh Sankian et al. 2018). However, in recent years, eutrophication of the major water resources and the pollution of the environment have caused widespread concerns about the release of nitrogen from farming activities (David R. Kanter et al. 2019). Consequently, in order to address these concerns, reuse of aquaculture water has become one of the technical and sustainable means or alternative (Yuan Junji et al. 2019). Thus the effective control of ammonia nitrogen is the key to aquaculture water reuse (Zong Xianzhu et al. 2019).

The main methods for controlling ammonia nitrogen in biofloc technology system include; ammonia assimilation by heterotrophic bacteria and nitrification by autotrophic bacteria (Hargreaves, J A. 2006; Schryver, P D et al. 2008). Bioflocs Technology Aquaculture Systems (BFTs) control ammonia nitrogen through the process of maintaining the appropriate $\mathrm{C} / \mathrm{N}$ to promote heterotrophic assimilation of ammonia nitrogen. In general, the $\mathrm{C} / \mathrm{N}$ in BFTs is high, which is beneficial to the growth of heterotrophic bacteria (Mirzakhani Neda et al. 2019) and the water characterized by higher suspended matter. BFT controls ammonia nitrogen through bacteria suspended in water and bacteria in flocs. Therefore, bacteria are an indispensable component of BFTs. Some of these are responsible for water purification through the removal of these toxic substances and provide suitable conditions for farmed animals (Burford et al. 1975). In addition, the changes in the intestinal flora structure caused by the type of biological 
flocculation, carbon sources, breeding objects, and the environment can all affect the distribution of microbial communities in biological flocs (Zhao P et al. 2012; Anand PSS et al. 2014; Yang Zhangwu et al. 2015).

The floral structure of the cultured water has a significant effect on the intestinal flora of cultured animals, which in turn affects their growth and welfare (Panigrahi et al. 2019). Yale et al. (2019) showed that the structure of the intestinal flora of $P$. vannamei is similar to that of the BFTs in which it is thriving. GIFT tilapia is a common breed for BFTs. Tilapia can directly feed on bioflocs in BFTs. Our previous study investigated the growth, digestive activity, welfare, cost-effectiveness, water quality dynamics (Luo et al., 2017) and nitrogen budget of tilapia in BFTs, has also been described in our previous paper (Cao et al., 2019). This study focused on characterizing the bacterial community in BFT water and bioflocs as well as the bacterial community in fish intestines reared in the BFT environment. The findings of this study will contribute to increasing the knowledge-base and understanding of bacterial communities in closed aquaculture systems and as well help improve the operational design of zero-exchange aquaculture systems and thus increase their sustainability.

\section{Materials And Methods}

\subsection{Cultured system}

The experiment was conducted in Shanghai Ocean University, China. Most of the time during the experiment, the air temperature was less than $10{ }^{\circ} \mathrm{C}$. The experiment used three large water tanks and two large air pumps for aeration. The operating volume of each water tank was 2 cubic meters. A $100 \mathrm{~L}$ bucket was used to settle the excess floc in each bucket and the supernatant from the bucket was returned to the BFT tank.

\subsection{Fingerlings of tilapia and feed used}

The tilapia fingerlings were obtained from a commercial fish farm (Wulonggang Aquatic Ltd., Guangdong, China). The fish were fed a commercial-pellet diet (Tongyi Special Feed Co., Ltd., Guangdong, China) that contained $12.0 \%$ water, $33 \%$ crude protein $(5.28 \% \mathrm{~N}), 2.0 \%$ crude lipids, $1.97 \% \mathrm{P}$ $\geq 1.4 \%$ lysine, $<12.0 \%$ crude ash, and $<8.0 \%$ crude fiber.

\subsection{Experimental design 2.3.1 Start-up of BFT}

All the tanks and water treatments were cleaned prior to filling with dechlorinated tap water. Commercial aquatic feed contained $\geq 48 \%$ crude protein, $\leq 17 \%$ crude ash and $\geq 4 \%$ crude lipid. The initial TSS was $200 \mathrm{mg} / \mathrm{L}$. Glucose was added to increase the input $\mathrm{C} / \mathrm{N}$ to $20: 1$. When the concentrations of $\mathrm{NH}_{3}-\mathrm{N}_{1} \mathrm{NO}_{2}{ }^{-}-$ $\mathrm{N}$ and $\mathrm{NO}_{3}{ }^{-}-\mathrm{N}$ were stable less than $0.33 \pm 0.04,0.06 \pm 0.03$ and $40.32 \pm 13.03 \mathrm{mg} / \mathrm{L}$, respectively. It was 
therefore considered that the start-up period of BFT was completed (Hargreaves, 2013). The start up period lasted for 45 days.

\subsubsection{Stocking and management}

Tilapia fingerling with initial mean weight $3.54 \pm 2.82 \mathrm{~g}(\mathrm{n}=30)$ were stocked at a density of $5.12 \pm$ $0.04 \mathrm{~kg} / \mathrm{m}^{3}$ per tank. In order to give time for the tilapia to adapt to the environment, the water temperature was maintained about $24^{\circ} \mathrm{C}$ for 20 days. Then the temperature decreased slowly and the water temperature was maintained in the range of 18 to $20^{\circ} \mathrm{C}$. By the time the air temperature increased up to $20^{\circ} \mathrm{C}$, the experiment was over. This culture lasted for a period of 64 days. The water was continuously aerated to maintain the DO within the range of $6-7.5 \mathrm{mg} / \mathrm{L}$ in each tank. Considering the high TSS contained, more aeration was supplied. The $\mathrm{pH}$ in all systems was maintained in the range of 7.0 to 7.5 by adding $\mathrm{NaHCO}_{3}$. In total $11.34 \mathrm{~kg}$ of $\mathrm{NaHCO}_{3}$ was added into BFT to supply the consumption of alkalinity and maintain $\mathrm{pH}$. PCL was used as the additional carbonate for BFT tanks as describe by Luo et al. (2018). Whenever the TSS level exceeded $600 \mathrm{mg} / \mathrm{L}$ in any BFT tank, some of the water containing flocs was taken out and put into the settling container. After settling for $1 \mathrm{~h}$, the supernatant was returned to the tank and the bioflocs were collected and recorded.

Fish were fed to apparent satiation three times a day (9:00, 14:00 and 19:00). Only dechlorinated tap water was added to each tank every day to compensate for water lost through evaporation and removal of redundant flocs.

\subsection{Analysis methods}

\subsubsection{Water quality parameters and air temperature}

Water temperature $\left({ }^{\circ} \mathrm{C}\right), \mathrm{DO}$ and $\mathrm{pH}$ were measured daily using a WTW meter (WTW Multi 3430 SETF, German). $\mathrm{NH}_{3}-\mathrm{N}, \mathrm{NO}_{2}{ }^{-}-\mathrm{N}, \mathrm{NO}_{3}{ }^{-}-\mathrm{N}$, total nitrogen (TN), total phosphate (TP), TSS were analyzed every four days according to standard methods (SEPA 2002). DOC was analyzed every four days using a Total Organic Carbon Analyzer (Multi N/C 2100, Analytikjenamulti, German). Air temperature was measured daily. Seven days were selected randomly to determine water temperature every $1 \mathrm{~h}$ from 6:00 to 24:00.

\subsubsection{PCR amplification and high-throughput sequencing}

All samples taken for the determination of bacterial community diversity were sent to Shanghai Meiji Biomedical Technology Co., Ltd. for PCR amplification and high-throughput sequencing. All samples in this experiment were PCR amplified targetting the V3-V4 region of $16 \mathrm{SrRNA}$ as a universal primer. The primer used were 338F (5'- ACTCCTACGGGAGGCAGCAG-3') and 806R (5'-GGACTACHVGGGTWTCTCATAT$\left.3^{\prime}\right)$. The reaction conditions of PCR were: denaturation at $95^{\circ} \mathrm{C}$ for $3 \mathrm{~min}$; denaturation at $95^{\circ} \mathrm{C}$ for $30 \mathrm{~s}$; annealing at $55^{\circ} \mathrm{C}$ for $30 \mathrm{~s}$; extension at $72^{\circ} \mathrm{C}$ for $45 \mathrm{~s}$ for 27 cycles, and then extension at $72^{\circ} \mathrm{C}$ for 10 min. The PCR amplification results were checked by $2 \%$ agarose gel electrophoresis, and the amplified samples were subsequently subjected to high-throughput sequencing. 
Sequences used for these analysis were deposited in GenBank accessions. The raw data were submitted to the NCBI Raw DataBFTe under the SRA accession ID PRJNA529947.

\subsection{Data processing}

The i-sanger cloud platform (www.i-sanger.com) was used to analyze and process the obtained data. The repeats and single sequences in the optimized sequence were removed, and the non-repeated sequences obtained were OTU clustered according to $97 \%$ similarity. Chimeras were removed to obtain the OTU representative sequence. The RDP (ribosomal dataBFTe project) classifier Bayesian algorithm was used to perform a taxonomic analysis of $97 \%$ similar OTU representative sequences and the taxonomic information represented by each OTU obtained. Analysis of Chao1 and simpson indices were done. Chao1 index represents the richness of the sample microbial community. The larger the value is, the richer it is. On the other hand, Simpson index represents the diversity of the sample microbial community. The larger the value, the lower the diversity. The calculation formula is as follows:

$$
S_{\text {Chao } 1}=S_{o b s}+\frac{n_{1}\left(n_{1}-1\right)}{2\left(n_{2}+1\right)}
$$

In the formula: SChao1 is the Chao1 index, $\mathrm{S}_{\mathrm{obs}}$ is the actual number of OTUs, $\mathrm{n} 1$ has only one sequence of OTUs, and $\mathrm{n} 2$ is the number of OTUs with only two sequences.

$$
D_{\text {simpson }} \frac{\sum_{i=1}^{S_{o b s}} n_{i}\left(n_{i}-1\right)}{N(N-1)}
$$

$D_{\text {Simpson }}$ in the formula is the Simpson index, $S_{\text {obs }}$ is the actual number of OTUs obtained, $n_{i}$ is the number of sequences contained in the $\mathrm{i}$-th OTU, and $\mathrm{N}$ is the number of all sequences.

In order to study the similarity and difference of microbial community composition between different samples, QIIME software was used to calculate the beat diversity distance matrix, and perform hierarchical clustering to construct a sample hierarchical clustering tree.

The water quality data obtained from this study was analysed using SPSS software (IBM Co.LtD version 20). Significant differences in the water quality parameters were determined using ANOVA. The analysed were presented in graphs.

\section{Results}

\subsection{Dissolved nitrogen syndrome and DOC/TN in the BFTs}


Ammonia nitrogen and nitrite were controlled at lower levels, with average concentrations of $1.56 \pm$ $0.76 \mathrm{mg} / \mathrm{L}, 1.58 \pm 0.56 \mathrm{mg} / \mathrm{L}$, and $0.47 \pm 0.29 \mathrm{mg} / \mathrm{L}, 0.09 \pm 0.04 \mathrm{mg} / \mathrm{L}$, and nitrate accumulation reached $336.91 \mathrm{mg} / \mathrm{L}$. Due to the added carbon source, the DOC/TAN of the BFT group was above 20 as shown in Fig. 1. The growth performance of tilapia and the detailed changes in other parameters using a similar design has been demonstrated in our previous study (Cao et al., 2019).

\subsection{Diversity and richness of bacteria community}

Samples of BFT water, floc, and fish intestines in BFT were used to analyze the flora structure. The bacterial community structures of the bioflocs were determined by Illumina high-throughput sequencing for 16S rRNA genes. The indices used to describe the richness and diversity of bacteria communities are given in Fig. 2. Chao 1 richness estimator and Shannon Index were used to describe the bacterial community richness and diversity respectively (Pei et al., 2012). With the increase of culture time, microbial richness in flocs; that is both the degree and diversity increased and the microbial diversity increased significantly. Its Simpson index decreased from 0.6449 to 00889.

\subsection{Microbial community distribution in the BFT system}

A total of 27 phylums, 320 genus, and 673 OTUs were found in the floc in the BFT system and the number of OTUs shared in the early and late breeding period was 212, as shown in Fig. 3.

In terms of phylum level, as shown in Fig. 4, the abundance of Firmicutes was $86 \%$ at the beginning of the culture, which was an absolute advantage, but was only $3 \%$ at the end. The abundance of Chlorofiexi which became the dominant bacteria at the end of breeding period was $43 \%$ but intially was only $3 \%$ at the beginning. Proteobacteria increased from the initial 4-26\% and Bacteroides increased from the initial $4-12 \%$ at the end. The dominance of Actinobacteria did not change significantly as it only $3 \%$ at the beginning and $2 \%$ at the end.

At the genus level, as shown in Fig. 4, Bacillus was the main species in the BFT tank during the initial stage of cultivation reaching $86 \%$, while the abundance of Bacillus spp decreased to $3 \%$ at the end of the cultivation. Also, Norank-f-Caldilineaceae was $40 \%$ at the end of the study. Initially it was Cetobacterium genus that was detected with $8 \%$ dominance at the end of the expeiment. The abundance of Flavobacterium was $2 \%$, the others were Norank-c-SBR2076 which had not been identified to the genus level. At the end, Norank-f-Saprospiraceae was also $2 \%$ and the similarity in the filter was similar. Reyranella and Norank-f-Cytophagaceae also made up $2 \%$ of the BFT at the end of the experiment.

\subsection{Microbial community distribution in the fish intestines}

In the intestinal tract of tilapia cultured in the BFT system, 15 phylums, 16 genera and 684 OTUs of bacteria were found.

During the entire breeding process, the intestinal bacterial community of the fish changed dramatically and as there were noticeable shifts in the dominance of bacterial phylum. The dominance of the 
Proteobacteria initially, was only $4 \%$, which increased to $20 \%$ at the end. Campylobacter phyllophyta increased from $7-16 \%$ and the Actinobacteria group increased from 12-20\%. Firmicutes increased from the original $15-20 \%$. It is worth noting that the dominance of the Chlamydia phylum in the intestines of both fish species at the end of the culture was $0.26 \%$, which was later increased to $1 \%$.

At the genus level, Cetobacterium, which initially accounted for $62 \%$, was only $13 \%$ at the end of the experiment. Bacillus, which was not detected at the beginning, increased to $16 \%$ at the end. The dominance of Microbacterium and Romboutsia was 3\%, which was not detected in the intestine. The unclassified bacteria norank-0-JG30-KF-CM45 belonging to the phylum Curvularia phylum with an initial dominance of $6 \%$ decreased to $0.19 \%$ at the end.

\section{Discussion}

\subsection{Analysis of microbial community and diversity of the BFT system}

Flocculation is the process of the combination of particles, algae and fungi in water through the action of flocs and heterotrophic microorganisms (Lu et al. 2010; De Schryver et al. 2008). Studies have shown that $\mathrm{C} / \mathrm{N}$ greater than 15 is conducive to the growth of heterotrophic bacteria (Goldman et al.1987). In this experiment, $\mathrm{C} / \mathrm{N}$ in the BFT group was maintained above 15 , which provided the sufficient conditions for the growth and reproduction of bacteria. In situ BFT system, the breeding objects are put together with the biological floc and the fish can ingest the floc (Azim et al.2008). So the microbial abundance in the BFT system decreased at the end of this experiment. A study by Zhao et al. (2012) showed that among the bacterial species found in the biological floc, Proteobacteria constituted a dominant bacteria group. The bacterial phyla in BFT are known to be involved in the beta deformation of flocs flora is important in addition to the nitrogen in the wastewater treatment of bacteria (Kapley et al. 2007). The nitrosation spirillum (Nitrosospira) and nitrosation belongs to bacterium (Nitrosomonas) as the main ammonia oxidizing bacteria (Ballinger lewis et al. 1998) in charge of the breakdown of nitrate nitrogen. Ammonia nitrogen convertion during the experiment was found in the floccules undergoing nitrosation by the bacterium. But the abundance was not high and may be due to the over-wintering temperature which was too low. This affected the proliferation of bacteria by inhibiting their growth. However, the ammonia nitrogen was controlled below the level of safe breeding. Somasundaram (2012), showed that the main nitrite oxidizing bacteria, and denitrifying spiral bacteria all function to translate nitrate nitrogen and dinitrogen. Additionally, in this experiment, the floccules were also found to contain nitration spiral bacteria genera which further proves that in BFT systems autotrophic nitrification phenomenon exists in the system.

In addition to autotrophic nitrification and heterotrophic assimilation, the maximum growth rate of heterotrophic bacteria in the bioflocculation system was significantly higher than that of nitrifying bacteria and the microbial biomass was 40 times higher than that of autotrophic nitrifying bacteria (Ebeling et al., 2006). Hargreaves, 2006). In this experiment, there was the advantage of the early 
establishment of the bacterium Bacillus genus, which reached an abundance of $86 \%$. Bacillus can secrete amylase and protease to degrade organic pollutants in the water, and can effectively inhibit pathogenic bacteria breeding under certain condition. The Bacillus can both improve the aquaculture water quality (Vijayalakshmi et al, 2003). When it is used as feed additive, it can promote the growth of farmed animals and enhance the body's immune and disease-resistant ability (Shih et al, 2001). In the later water environment, $C$. Iustrum was the dominant flora, which was inconsistent with the dominant flora of Proteobacteria. This was also observed Xia Yun et al. (2012) in the biological floc. C. Iustrum is a facultative anaerobe that can carry out photosynthesis but does not produce oxygen This indicated the existence of anaerobic environment in the culture system, which may be related to the high density of the culture in the later stage. In the later period of culture, the phylum abundance of Fusarium increased from $0.5-2 \%$, mainly belonging to the genus Isosphaera. It is an ammonia-oxidizing bacteria, which can directly convert ammonia nitrogen and nitrite nitrogen into nitrogen through anaerobic ammonia oxidation (Ballinger et al., 1998). It is the main bacteria that can remove ammonia nitrogen in the system. At the genus level, the genus Xanthobacter reached $22 \%$. This type of facultative anaerobic bacteria can use nitrate and nitrite as electron acceptor to conduct denitrification in the anaerobic environment. Nitrate is converted into reduction products and organic matter is oxidized (Djordje et al., 2020).

\subsection{Effects of culture water on intestinal microorganisms of fish}

Gut microbes can adjust the physiological activities of the host, promote metabolism and growth of fish (Clements et al, 2014). Research shows that fish intestinal microflora depends on the culture water, their genetics, diets and fish aspects of influence (Bolnick et al, 2014). Therefore, different systems of cultivation, can influence the structure of intestinal flora and also cause changes in the fish. Xia et al. (2012) found that dominant bacteria in flocculation significantly affected the intestinal flora structure of farmed fish. In this experiment, Actinomycetes had the highest microbial abundance in the intestinal tract of fish, and the abundance of Clostridium and Firmicutes was also high. The structural selection effect of intestinal flora in fish is influenced by aerobic environment and immune factors in the intestinal tract of aquatic animals. Not all microorganisms in the water will colonize and proliferate in the intestinal tract of fish (Rawls et al. 2006; Giatsis et al, 2015).

In order to better study the impact of floc on fish intestinal flora structure, data from another study (Cao et al., 2019) was introduced. This was used to detect the flora structure of water body, biological filter, fish intestinal tract and gills in Recirculating Aquaculture System (RAS). By comparison, it was found that Proteobacteria had the highest microbial abundance in the fish intestinal tract of RAS and Actinobacteria had the highest microbial abundance in the fish intestinal tract of BFT. The richness of Fusobacteria and Firmicutes in the fish intestinal tract of BFT was significantly higher than that of RAS. Thick walled fungus prioritize with Bacillus. Research shows that Bacillus can produce a large amount of extracellular enzymes, inhibit the growth of pathogenic microorganisms in fish bowel, improve body immunity and promote the decomposition of organic matter as well as improve the utilization rate of bait (Bolnick et al, 2001). The BFT intestinal samples had $16 \%$ of Bacillus genus, while it was only $0.1 \%$ of the RAS group. 
Cetobacterium can produce vitamin B12, which promote the metabolism of fish, protecting the nervous system and inhibiting the growth of harmful bacteria. However, the abundance of Cetobacterium in the BFT group was $13 \%$, while that in the RAS group was only $3 \%$. BFT aquaculture water significantly changed. The culture water of the BFT system, significantly influenced the bacterial community structure of the fish intestinal tract, indicating that different breeding environments can significantly affect the intestinal microorganisms of fish. Moreover, the abundance of beneficial bacteria such as Bacillus and Cetobacterium in the fish intestinal tract of the BFT breeding mode is higher than that in the RAS breeding mode, which leads to the difference in the diversity and richness of intestinal microorganisms in the fish cultured in the two systems.

The main functions of heterotrophic assimilation in BFT system of the current study was carried out by Bacillus, Campylobacter, and Flavobacterium. This bacterial composition was an indication that denitrification was ongoing. The BFT breeding model had a higher abundance of beneficial flora, which can inhibit the reproduction of pathogenic bacteria, reduce the incidence during breeding, improve digestive ability and promote the healthy growth of breeding species.

\section{Declarations}

\section{Acknowledgement}

This study was funded by the Shanghai Science and Technology Commission Project (19DZ2284300).

\section{Authors' contributions}

Conceptualization: $Y Z$ and $B C$; data collection and analysis: $Y Z, B C$ and $G A$; drafting of the manuscript: $Y Z, G A$, and GL; review and editing: $G L, Y Z$ and $Y A L$. All authors read and approved the final manuscript.

\section{Funding}

This study was funded by the Shanghai Science and Technology Commission Project (19DZ2284300)

\section{Data availability}

All data are fully available on request.

\section{Compliance with ethical standards}

\section{Ethics approval and consent to participate}

This article does not contain any studies with human participants or vertebrate animals performed by any of the authors.

\section{Consent for publication}

This manuscript does not contain any individual person's data. 


\section{Competing interests}

The authors declare that they have no competing interests.

\section{References}

1. Anand PSS, Kohli MPS, Kumar S, Pailan GH (2014) Effect of dietary supplementation of biofloc on growth performance and digestive enzyme activities in penaeus monodon. Aquaculture 418419:108-115. doi:10.1016/j.aquaculture.2013.09.051

2. Azim ME, Little DC (2008) The biofloc technology (bft) in indoor tanks: water quality, biofloc composition, and growth and welfare of nile tilapia (Oreochromis niloticus). Aquaculture 283(14):29-35. doi:10.1016/j.aquaculture.2008.06.036

3. Ballinger SJ, Head IM, Curtis TP, Godley AR (1998) Molecular microbial ecology of nitrification in an activated sludge process treating refinery wastewater. Water Sci Technol 37(4-5):105-108. doi:10.1016/S0273-1223(98)00091-2

4. Ballinger SJ, Head IM, Curtis TP, Godley AR (1998) Molecular microbial ecology of nitrification in an activated sludge process treating refinery wastewater. Water Sci Technol 37(4-5):105-108. doi:10.1016/S0273-1223(98)00091-2

5. 10.1016/j.aquaeng.2019.102026

Cao B, Abakari G, Luo G, Tan H, Wu X (2019) Comparative analysis of nitrogen and phosphorus budgets in a bioflocs aquaculture system and recirculation aquaculture system during over-wintering of tilapia (GIFT, Oreochromis niloticus). Aquacultural Engineering 89. doi:

10.1016/j.aquaeng.2019.102026

6. Bolnick DI, Snowberg LK, Hirsch PE, Lauber CL, Knight R, Caporaso JG (2014) Individuals'diet diversity influences gut microbial diversity in two freshwater fish (threespine stickleback and eurasian perch). Ecol Lett 17(8):979-987. doi:10.1111/ele.12301

7. Burford JR, Bremner JM (1975) Relationships between the denitrification capacities of soils and total, water-soluble and readily decomposable soil organic matter. Soil Biol Biochem 7(6):389-394. doi:10.1016/0038-0717(75)90055-3

8. Clements KD, Angert ER, Montgomery WL, Choat JH (2014) Intestinal microbiota in fishes: what's known and what's not. Mol Ecol 23(8):1891-1898. doi:10.1111/mec.12699

9. David RK, Fabio B, Susanna K, Adrian L, Oene O, Aimable U (2019) Nitrogen pollution policy beyond the farm. Nature Food 1:27-32. doi:10.1038/s43016-019-0001-5

10. De Schryver P, Verstraete W (2008) Nitrogen removal from aquaculture pond water by heterotrophic assimilation in lab-scale sequencing batch reactors. Bioresour Technol 100(3):1162-1167. doi:10.1016/j.biortech.2008.08.043

11. Djordje B, Alvaro S (2020) The ecology and evolution of microbial metabolic strategies. Curr Opin Biotechnol 62:123-128. doi:10.1016/j.copbio.2019.09.003 
12. Ebeling JM, Timmons MB, Bisogni JJ (2006) Engineering analysis of the stoichiometry of photoautotrophic, autotrophic, and heterotrophic removal of ammonia-nitrogen in aquaculture systems. Aquaculture 257(1):346-358. doi:10.1016/j.aquaculture.2006.03.019

13. Giatsis C, Sipkema D, Smidt H, Heilig H, Benvenuti G, Verreth J, Verdegem M (2015) The impact of rearing environment on the development of gut microbiota in tilapia larvae. Sci Rep 5:18206. doi:10.1038/srep18206

14. Goldman JC, Dennett CMR (1987) Regulation of gross growth efficiency and ammonium regeneration in bacteria by substrate c:n ratio. Limnol Oceanogr 32(6):1239-1252. doi:10.4319/lo.1987.32.6.1239

15. Guozhi L, Nan Z, Shengli C, Hongxin T, Zefeng L (2017) Nitrogen dynamics, bacterial community composition and biofloc quality in biofloc-based systems cultured Oreochromis niloticus with poly- $\beta$ hydroxybutyric and polycaprolactone as external carbohydrates. Aquaculture 479(1):732-741. doi:10.1016/j.aquaculture.2017.07.017

16. Guozhi L, Zefeng L, Jinfang G, Zhiwei H, Hongxin $T$ (2018) Nitrate removal efficiency and bacterial community of polycaprolactone-packed bioreactors treating water from a recirculating aquaculture system. Aquaculture International volume 26:773-784. doi:10.1007/s10499-018-0251-5

17. Hargreaves JA (2006) Photosynthetic suspended-growth systems in aquaculture. Aquacult Eng 34(3):344-363. doi:10.1016/j.aquaeng.2005.08.009

18. Hargreaves JA (2006) Photosynthetic suspended-growth systems in aquaculture. Aquacult Eng 34(3):344-363. doi:10.1016/j.aquaeng.2005.08.009

19. Junji Y, Jian X, Deyan L, Hojeong K, Tiehu H, Sunghyun K, Yongxin L, Freeman C, Weixin D (2019) Rapid growth in greenhouse gas emissions from the adoption of industrial-scale aquaculture. Nature Climate Change 9:318-322. doi:10.1038/s41558-019-0425-9

20. Kapley A, Prasad S, Purohit HJ (2007) Changes in microbial diversity in fed-batch reactor operation with wastewater containing nitroaromatic residues. Biores Technol 98(13):2479-2484. doi:10.1016/j.biortech.2006.09.012

21. Lu L, Guzhi L, Hongxin T, Dachuan S (2010) Bioflocs technology application in aquacultural water treatment. Fishery Modernization 37(6):6-14 doi: 1007-9580(2010)06-06-06

22. Mirzakhani N, Ebrahimi E, Jalali SAH, Ekasari J (2019) Growth performance, intestinal morphology and nonspecific immunity response of Nile tilapia (Oreochromis niloticus) fry cultured in biofloc systems with different carbon sources and input C:N ratios. Aquaculture 512(15). doi:10.1016/j.aquaculture.2019.734235

23. Panigrahi A, Saranya C, Sundaram M, Vinoth Kannan SR, Das Rasmi R, Sathish S, Rajesh P, Otta SK (2018) Carbon: Nitrogen (C:N) ratio level variation influences microbial community of the system and growth as well as immunity of shrimp (Litopenaeus vannamei) in biofloc based culture system. Fish Shellfish Immunol 81:329-337. doi:10.1016/j.fsi.2018.07.035

24. Pei Z, Jie H, Xiuhua W, Xiaoling S, Conghai Y, Xuguang Z, Guocheng W (2012) The application of bioflocs technology in high-intensive, zero exchange farming systems of Marsupenaeus Japonicus. 
Aquaculture 354-355:97-106. doi:10.1016/j.aquaculture.2012.03.034

25. Rawls JF, Mahowald MA, Ley RE, Gordon Jl (2006) Reciprocal gut microbiota transplants from zebrafish and mice to germ-free recipients reveal host habitat selection. Cell 127(2):423-433. doi:10.1016/j.cell.2006.08.043

26. Schryver PD, Crab R, Defoirdt T, Boon N, Verstraete W (2008) The basics of bioflocs technology: the added value for aquaculture. Aquaculture 277(3-4):125-137.

doi:10.1016/j.aquaculture.2008.02.019

27. Shih IL, Van YT, Yeh LC, Lin HG, Chang YN (2001) Production of a biopolymer flocculant from Bacillus Licheniformis and its flocculation properties. Biores Technol 78(3):267-272. doi:10.1016/S0960-8524(01)00027-X

28. Somasundaram K, El-Deiry WS (2012) Characterization of nitrifying bacteria in marine recirculation aquaculture systems with regard to process optimization. J Biomed Opt 14(9):1047-1057

29. Vijayalakshmi SP, Raichur AM (2003) The utility of bacillus subtilis as a bioflocculant for fine coal. Colloids surfaces B: Biointerfaces 29(4):265-275. doi:10.1016/S0927-7765(03)00005-5

30. Yale D, Xiangyang $X$, Xuwang $Y$ (2019) Effect of stock density on the microbial community in biofloc water and Pacific white shrimp (Litopenaeus vannamei) gut microbiota. Appl Microbiol Biotechnol 103(10):4241-4252. doi:10.1007/s00253-019-09773-4

31. Yun X, Ermeng Y, Jun X, Deguang Y, Guangjun W, Zhifei L, Haiying W, Wangbao G (2012) Analysis of bacterial community structure of Bio-Floc by PCR-DGGE. Journal of Fisheries of China 36(10):15631571. doi:10.3724/SP.J.1231.2012.27998

32. Zhangwu Y, Keng Y, Zhe Z, Zhengliang L, Hui G (2015) Research on the biofloc bacterial community structure during larval rearing of Litopenaeus vannamei using metagenome sequencing. Journal of Fujian Fisheries 37(2):91-97. doi:10.14012/j.cnki.fjsc.2015.02.001

33. Zhao P, Huang J, Wang XH, Song XL, Yang CH, Zhang XG (2012) The application of bioflocs technology in high-intensive, zero exchange farming systems of Marsupenaeus Japonicus. Aquaculture 354-355:97-106. doi:10.1016/j.aquaculture.2012.03.034

34. Zhao P, Huang J, Wang XH, Song XL, Yang CH, Zhang XG (2012) The application of bioflocs technology in high-intensive, zero exchange farming systems of Marsupenaeus Japonicus. Aquaculture 354-355(2):97-106. doi:10.1016/j.aquaculture.2012.03.034

35. Zohreh S, Sanaz K, Yioh K, Sangmin L (2018) Effects of dietary inclusion of yellow mealworm (Tenebrio molitor) meal on growth performance, feed utilization, body composition, plasma biochemical indices, selected immune parameters and antioxidant enzyme activities of mandarin fish (Siniperca scherzeri) juveniles. Aquaculture 496:79-87. doi:10.1016/j.aquaculture.2018.07.012

36. Zongxian Z, Danli J, Bijun L, Hui Q, Zining M, Haoran L, Junhong X (2019) Differential Transcriptomic and Metabolomic Responses in the Liver of Nile Tilapia (Oreochromis niloticus) Exposed to Acute Ammonia. Mar Biotechnol 21(4):488-502. doi:10.1007/s10126-019-09897-8

\section{Tables}


Table 1

Sample label and corresponding sample

\begin{tabular}{|ll|}
\hline Sample number & Sample name \\
\hline BFT1 & BFT group initial floc samples \\
\hline BFT2 & BFT group terminal floc samples \\
\hline CHCS & Initial fish intestinal sample \\
\hline BFTCH & Intestinal samples of BFT fish \\
\hline SCS & Sample of the gills of the Initial fish \\
\hline BFTS & Gill samples from BFT fish \\
\hline
\end{tabular}

Figures
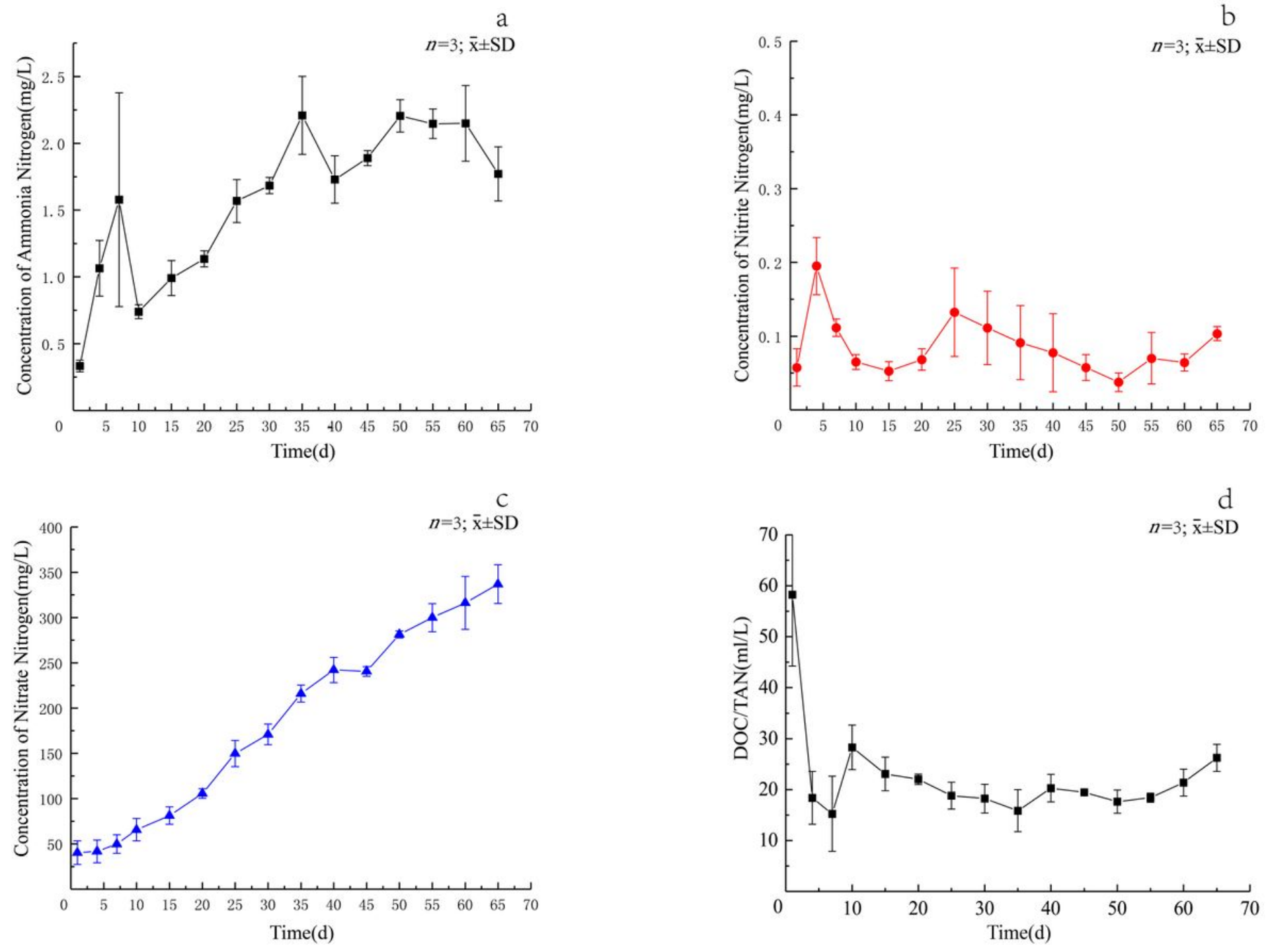

Figure 1 
Changes in dissolved inorganic nitrogen and DOC/TAN.
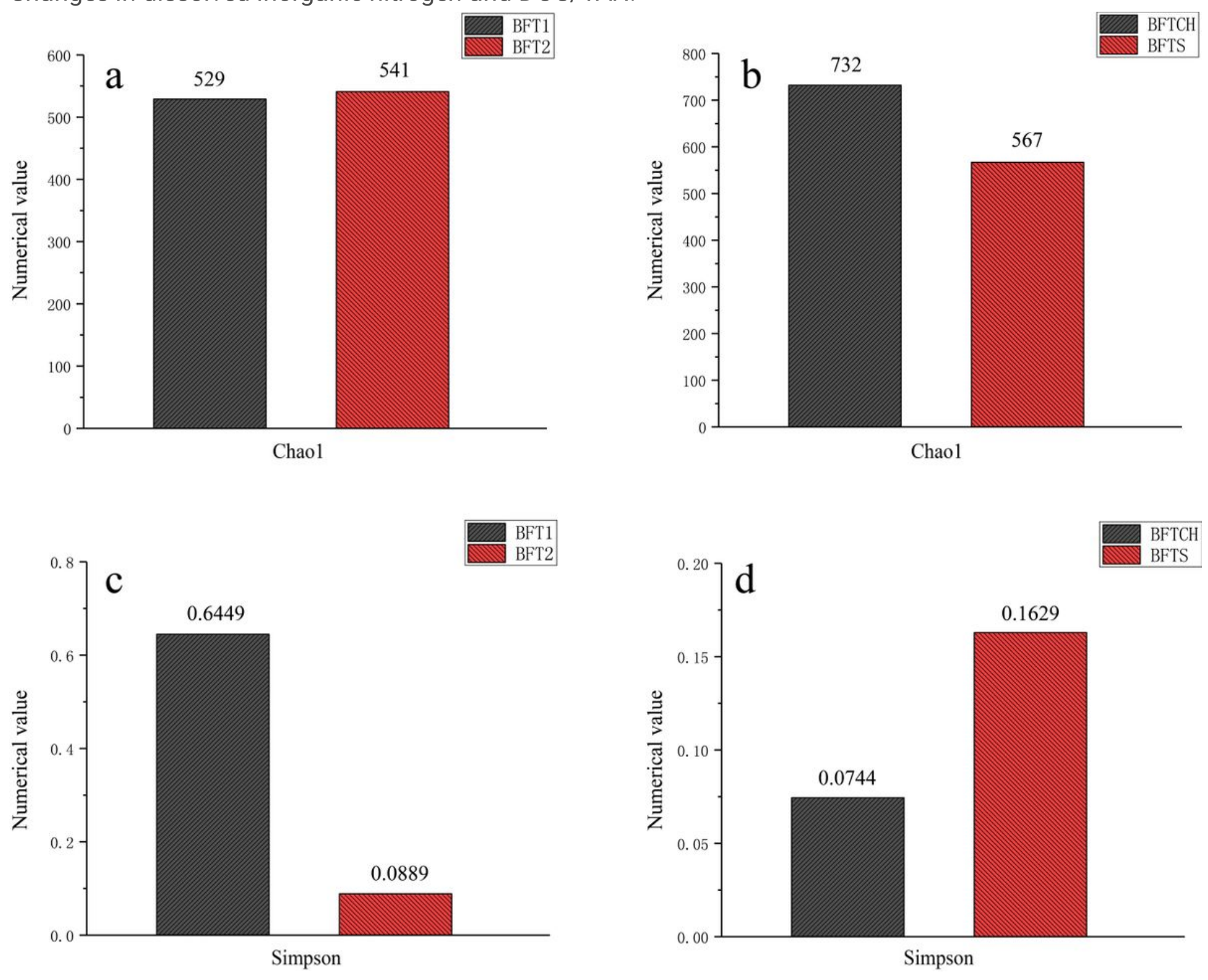

Figure 2

Chao1 index, BFT floc (a), BFT fish gut and gill (b); Simpson index, BFT floc (c), BFT fish gut and gill (d). 


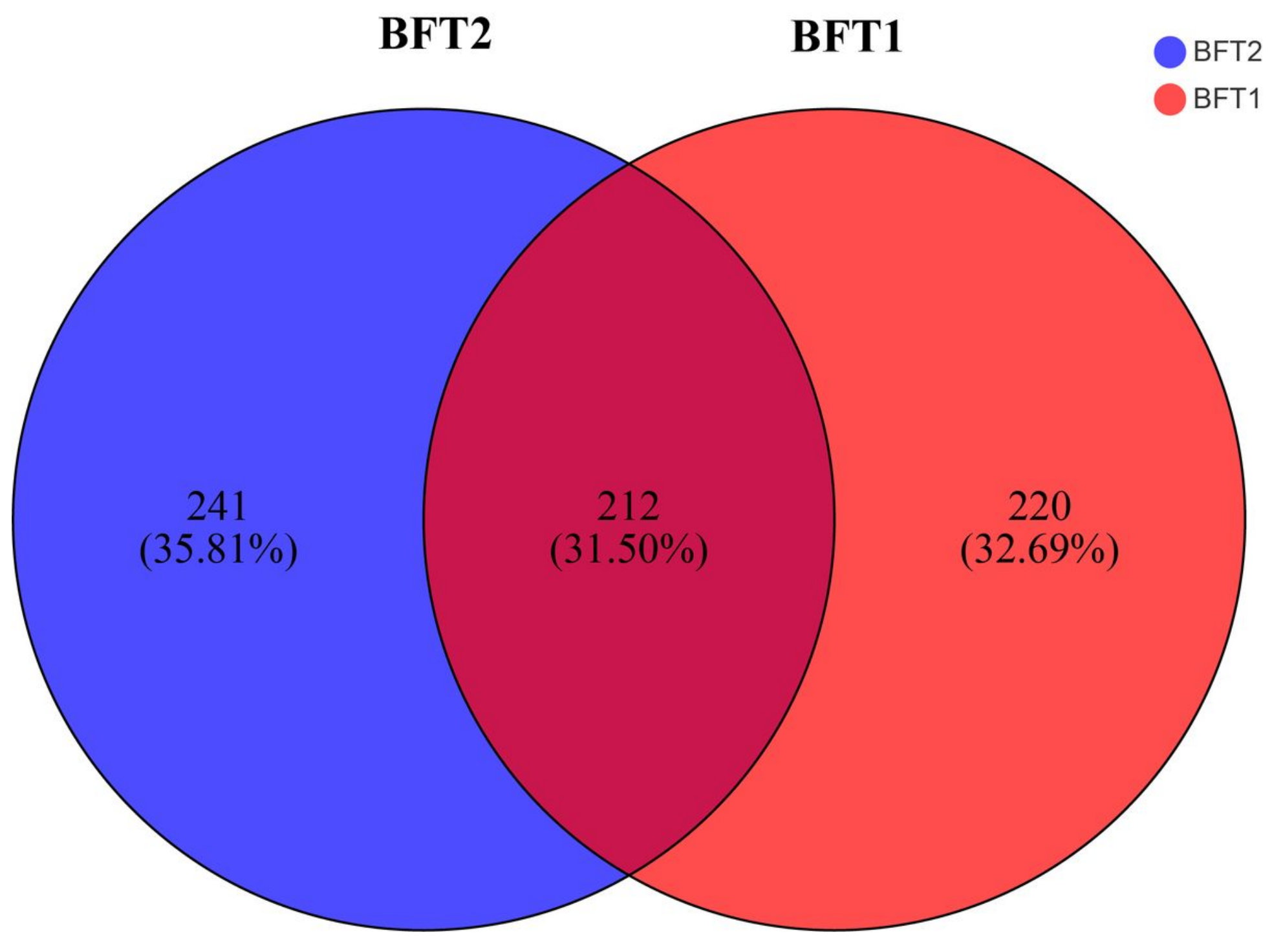

Figure 3

Venn diagram showing OTUs in the flocs from the BFT system
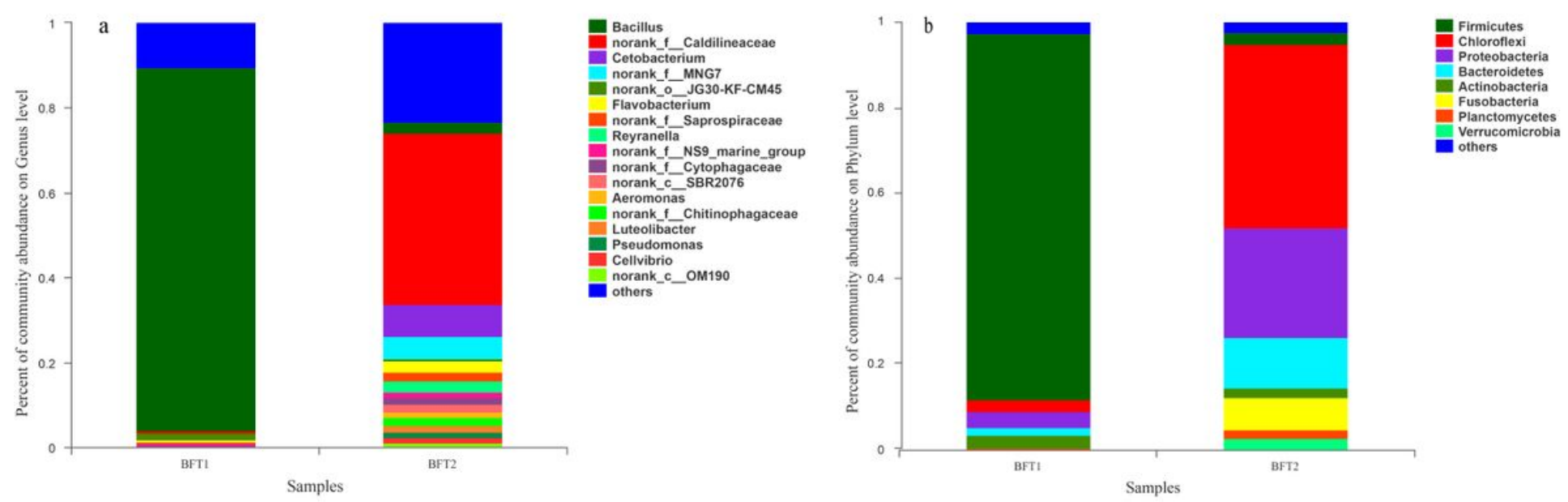
Figure 4

Floc microbial structure in the BFT system(phylum level and genus level)

a
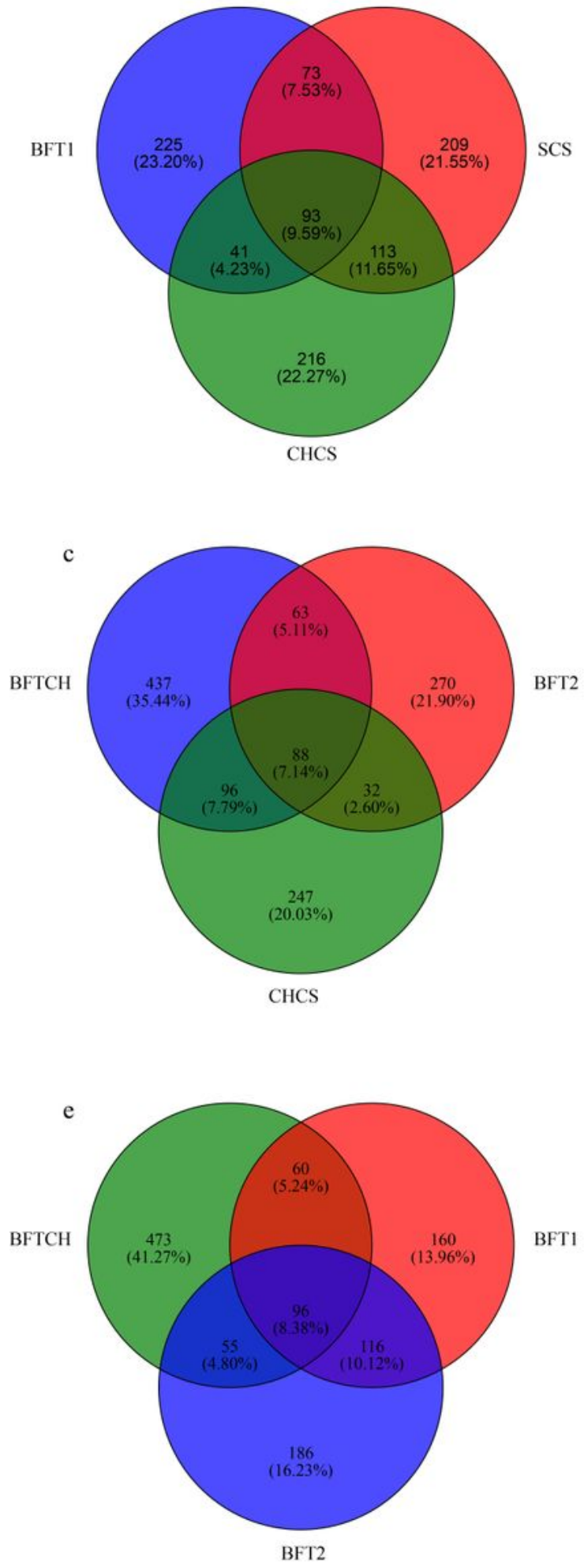

b
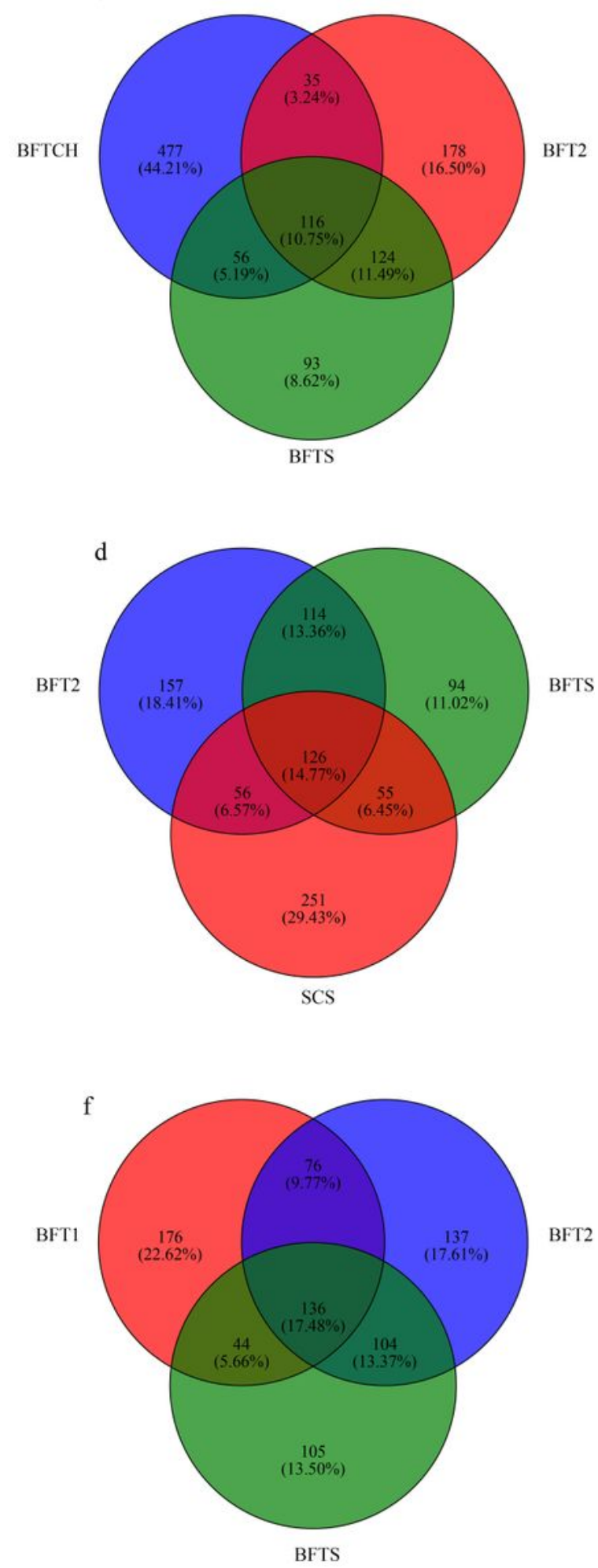

Figure 5

Venn diagrams showing OTUs. 

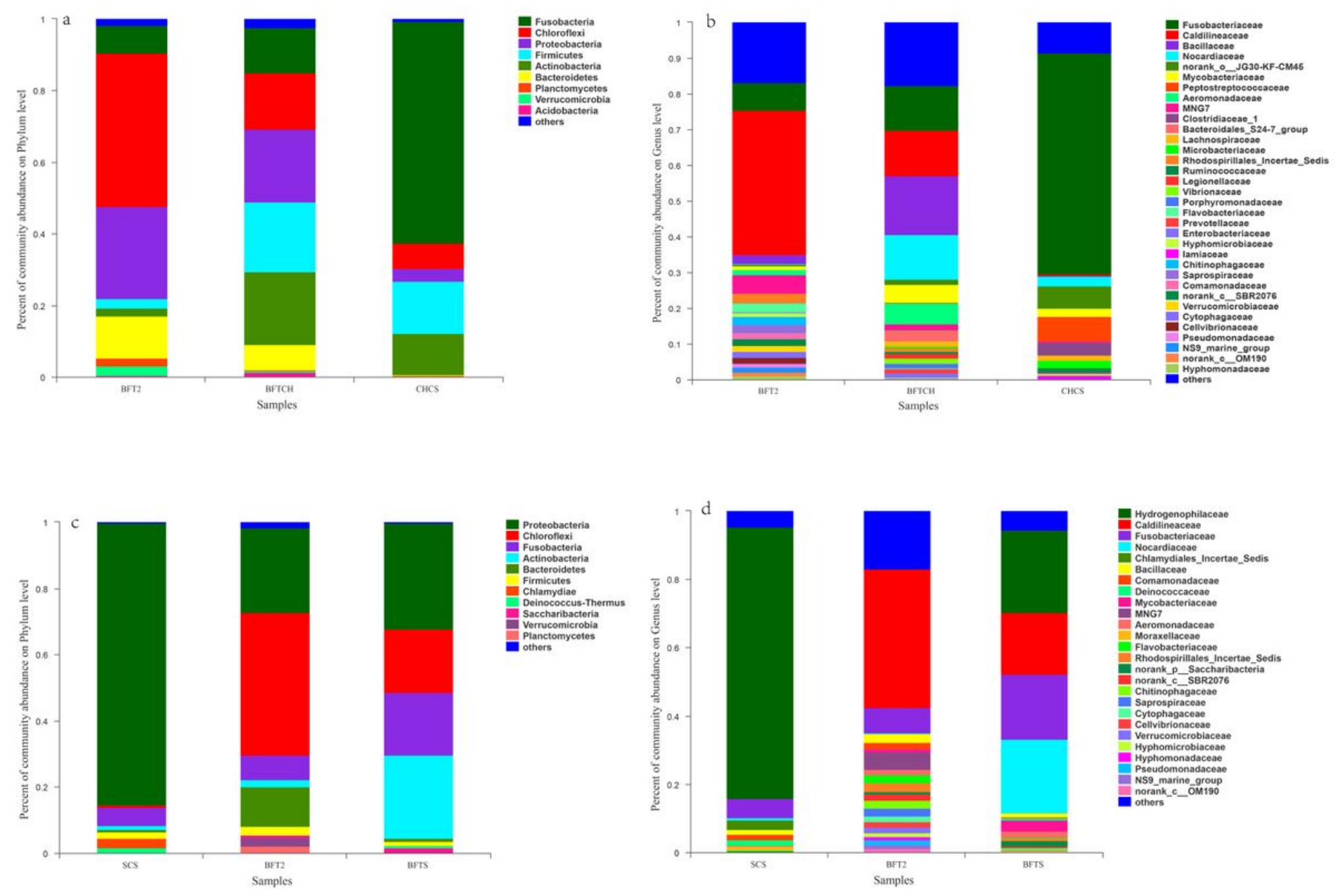

Figure 6

Microbial structure in BFT囚phylum level and genus level囚. 